\title{
Computer Simulation of Solution/Electrode Interfaces
}

\author{
Fernando M.S. Silva Fernandes, ${ }^{\text {a, }}$ Rui P.S. Fartaria, a,b \\ Diogo A.R.S. Latino, ${ }^{\text {a,c }}$ Filomena F.M. Freitas ${ }^{\text {a }}$ \\ ${ }^{a)}$ Molecular Simulation Group, Centre of Molecular Sciences and Materials, Department of \\ Chemistry and Biochemistry, Faculty of Sciences, University of Lisboa, 1749-016, Lisboa, \\ Portugal \\ ${ }^{b)}$ Department of Chemical and Process Engineering, University of Strathclyde, \\ Glasgow, GI IXJ \\ ${ }^{c)}$ REQUIMTE, CQFB, Department of Chemistry, Faculty of Sciences and Technology, \\ New University of Lisboa, 2829-516 Caparica, Portugal
}

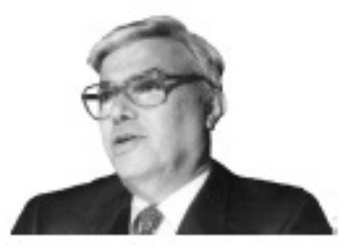

\section{In Honour of Professor César Viana}

\begin{abstract}
This article is based on the plenary lecture that I was invited to present in the XIV Encontro da Sociedade Portuguesa de Electroquímica and X Iberic Meeting of Electrochemistry, a meeting which was "a tribute to the late Professor César Viana". The best way I found to honour his memory was to review the highlights of a recent investigation on the computer simulation of solution/electrode interfaces carried out at our molecular simulation group, which would never happen without the enthusiasm and support of Prof. César Viana.

In this paper we focus on the determination, from first principles, of the interaction potentials between ethanol and gold surfaces aiming at their use in the computer simulation of adsorption and self-assembly processes on noble metal electrodes. An analytical force field has been proposed and fitted to DFT results, by means of genetic algorithms. The force field has been tested against Monte Carlo simulations. Finally, the non-trivial, or even impossible, task of finding analytical functions that accurately match $a b$ initio/DFT data, when many molecular degrees of freedom are involved, is briefly reviewed. The alternative of using neural networks to approach potential energy surfaces (PES) is presented and applied to the specific case of the ethanol-Au interactions.

The article is signed by the persons who mainly contributed to this work. They all praised very much Prof. César Viana. It is our tribute to his memory.
\end{abstract}

Keywords: Prof. César Viana, ethanol, gold, force field, DFT, Monte Carlo, genetic algorithms, neural networks.

\footnotetext{
*Corresponding author. E-mail address: fsilva @fc.ul.pt
} 


\section{Introduction}

I (F. Fernandes) met Professor César Viana in 1966. At the time, he was a young Assistant Professor of Chemistry in the Faculty of Sciences, University of Lisboa. He had recently returned from Southampton University, England, after his Ph.D. under the supervision of Professor Graham Hills. I was a $2^{\text {nd }}$ year undergraduate student of chemistry. The empathy that soon grew up between us gave birth to a strong and permanent friendship for life.

César Viana was an upright and good man of very many duties and passions, a distinguished teacher and researcher who played a relevant national and international role, particularly in our Department of Chemistry and Biochemistry [1]. I believe that the countless facets of his fascinating personality can be conveyed by the words of the poet Walt Whitman: "Do I contradict myself? Well then, I contradict myself. I am large. I contain multitudes".

After his return from England, César Viana created a research group on Chemical Kinetics and Thermodynamics with another Ph.D. colleague and some undergraduate students. I joined the group in 1969, the last year of my graduation. As coordinator and supervisor, César introduced the students to the scientific research and spurred their main scientific interests. "Think freely like the wind" seemed to be one of his soundless messages.

In such a pleasant and stimulating environment, I expressed the desire of dedicating myself to theoretical and computational chemistry. César, soon caressed the idea and, by means of him, I went to Southampton University to study computer simulation by molecular dynamics and Monte Carlo, also under the supervision of Graham Hills. After my Ph.D. in 1977, I returned to César's group then integrated in the Centre for Electrochemistry and Kinetics (CECUL) founded in 1975 and coordinated by Professor Fernando Barreira, a distinguished full professor and electrochemist of our Department. Sadly, Fernando Barreira died in 1976, after a brutal car accident. Since then, César Viana assumed the coordination of CECUL until 2003, the year after his jubilee as full professor. Due to strategic reasons, CECUL was closed in 2006 and its members and research groups joined other research units of our Department.

During the 25 years as scientific coordinator, César supervised a considerable number of research projects and Ph.D.'s of Portuguese and foreign students, and stimulated the realization of several Ph.D.'s abroad, that is, he created a school of scientific research.

With his accordance and permanent interest, a group on molecular simulation was born after my return from England.

In this article we shall review some recent results on the computer simulation of solution/electrode interfaces, obtained in our group. It is based on the plenary lecture that I presented in the XIV Encontro da Sociedade Portuguesa de Electroquímica and X Iberic Meeting of Electrochemistry. It is signed by the persons who mainly contributed to the work. They all praised very much César Viana. It is our tribute to his memory. 
Experimental advancements in interfacial electrochemistry have enabled the determination of structures and processes on the solid-liquid interface at a molecular level. Theoretically, the molecular description of such structures and processes in a quantitative manner is still in its infancy. On the one hand, the sui generis nature of the liquid state, the existence of solvated species and the longrange Coulomb interactions lead to considerable numerical and theoretical efforts. On the other hand, the appropriate incorporation of external electric fields or electrochemical potentials is not trivial. Still, there has been important progress in the theoretical description of the solid-liquid interfaces, including the modelling of complex reactions at electrodes from first-principles. The state of the art has been recently reviewed in a symposium exclusively dedicated to the theoretical challenge of the solid-liquid interface [2].

The present article is mainly concerned with the determination of interaction potentials from first-principles, between ethanol and $\mathrm{Au}(111)$ surfaces, and their use in Monte Carlo simulations of the adsorption of ethanol. The non-trivial, or even impossible, task of finding analytical functions that accurately match $a b$ initio/DFT data, when many molecular degrees of freedom are involved, is also briefly reviewed. The alternative of using neural networks to approach potential energy surfaces (PES) is presented and applied to the specific case of the ethanol$\mathrm{Au}$ interactions.

\section{Adsorption and self-assembly}

Since the end of last century, special attention has been given to the way of selectively modifying the surface properties of metals and semiconductors by the adsorption of organic molecules, which can form films of organized structures.

Self-assembly provides a powerful method for the preparation of organized, stable and versatile organic monolayers onto metallic surfaces, with a defined composition and close-packed structure. The self-assembly process consists of the chemisorption of species onto surfaces followed by their spontaneous organization, and the resulting films are known as self-assembled monolayers (SAMs) [3-6]. SAMs constitute a great promise regarding applications in different areas. The research in this field started about the 1980s and it has been one of the major research fields regarding, for example, photovoltaic developments, biosensors and corrosion prevention.

SAMs can be prepared using different types of molecules and substrates. Typically, an alkane chain, with $>=10$ methylene units, and a head group with a strong preferential adsorption to the substrate are used. Thiol $(\mathrm{S}-\mathrm{H})$ head groups and $\mathrm{Au}$ substrates are usually chosen due to their well-known chemical affinity. The thiol molecules adsorb readily, from solution, onto gold, creating a dense monolayer with the tail chains pointing outwards the surface. By using thiol molecules with different chain lengths, the resulting chemical surface functionality can be varied within wide limits. It is also possible to chemically functionalize the tail chains after the formation of SAMs.

Potential energy surfaces (PES) are crucial to study reactive and non-reactive chemical systems by molecular simulations. To investigate the mechanisms 
involved in the adsorption and self-assembly of solvated molecules on noblemetal electrodes, the PES should describe the interactions between the molecular species present in the liquid phase as well as the interactions between those species and the electrodes, as a function of distances and orientation angles.

One of our recent studies [7,8] is focused on the adsorption and self-assembly of alkylthiols, solvated by ethanol, on $\mathrm{Au}(111)$ surfaces, regarding the mechanisms of physisorption and chemisorption, the formation of self-assembled monolayers and the structure of the double-layer.

To the best of our knowledge, however, there is a lack of force fields, based on quantum mechanical calculations, for the interaction of ethanol with gold electrodes, in particular relatively to the Au(111) surface. As such, we have proposed a force field, from Density Functional Theory (DFT) calculations, aiming at the simulation of those heterogeneous systems by Monte Carlo or molecular dynamics.

\section{DFT calculations}

DFT is a powerful approach to deal with electronic correlation effects, which play an important role particularly in systems containing transition metal atoms. The theory level chosen for the calculations was the B3LYP method with the LanL1MB basis set applied to the Au atoms and the 6-31G basis set for the $\mathrm{H}, \mathrm{C}$ and $\mathrm{O}$ atoms [8].

To model the ethanol-Au(111) PES we used a cluster of $14 \mathrm{Au}$ atoms, representing the surface, and one ethanol molecule in the equilibrium gas phase configuration calculated by geometry optimization.

To probe the ethanol-gold interactions, three sites of the gold surface were chosen, as shown in Fig. 1: the top (TOP) site where the $\mathrm{O}$ atom approaches the surface over an Au atom of the $1^{\text {st }}$ layer; the hcp site, named hollow1 (H1), and the fcc site, named hollow2 $(\mathrm{H} 2)$ where the $\mathrm{O}$ atom approaches the surface in the direction of the centre of a triangle formed between three $\mathrm{Au}$ atoms of the $1^{\text {st }}$ layer. For the site $\mathrm{H} 1$ the triangle has an Au atom of the $2^{\text {nd }}$ layer at the centre.

The ethanol-Au(111) ${ }_{14}$ cluster interaction energy as a function of the distance and orientation, relatively to the gold cluster surface, is defined as

$$
\mathrm{U}_{\text {ethanol- }-\mathrm{Au}_{14}}(r, \alpha, \beta)=\mathrm{U}_{\text {ethanol }+\mathrm{Au}_{14}}(r, \alpha, \beta)-\mathrm{U}_{\mathrm{Au}_{14}}-\mathrm{U}_{\text {ethanol }}
$$

where $U_{\text {ethanol }+\mathrm{Au}_{14}}$ is the energy of the system composed by the ethanol molecule and the cluster; $\mathrm{U}_{\mathrm{Au}_{14}}$ and $\mathrm{U}_{\text {ethanol }}$ are, respectively, the energies of the isolated cluster and ethanol molecule; $r$ is the distance from the ethanol $\mathrm{O}$ atom to the plane of the first layer of the $\mathrm{Au}(111)$ surface; $\alpha$ is the angle between the $\mathrm{O}-\mathrm{H}$ bond and the normal to the surface, and $\beta$ is the angle between the O-H-C plane and the H-O-normal to the surface plane. 


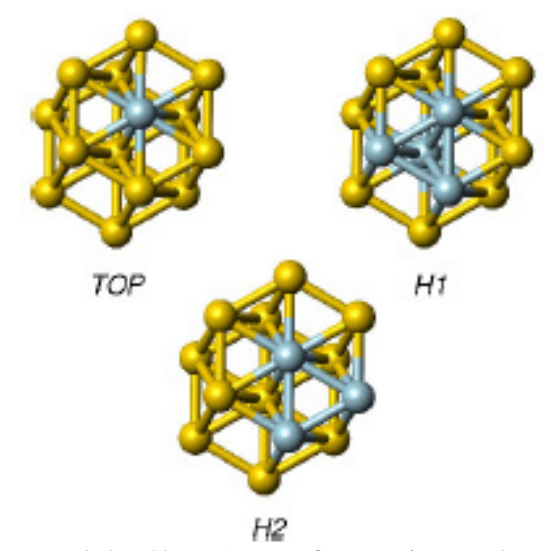

Figure 1. The top, hollow1 and hollow2 surface sites chosen to set up the ethanol-Au interaction.

The orientations for the ethanol molecule were selected to span a wide range of situations like the ones presented in Fig. 2, with the notation $\alpha / \beta$. For each orientation, the $\mathrm{U}_{\text {ethanol-Au }}$ energy was evaluated at several values of $r$. The interaction energy profiles are displayed in Fig. 3. The results show [8] that, in general, the strongest binding occurs for the orientations where the $\mathrm{O}$ atom is towards the surface and the $\mathrm{CH}_{3}$ group away from it. The orientations $180 / 180$ and 90/0, with the ethyl group turned to the surface, are always the most repulsive ones. The preferential site for the adsorption is the TOP one, at the 90/180 orientation where the $\mathrm{O}-\mathrm{H}$ bond is parallel to the surface, with the minimum interaction energy of $\sim-19 \mathrm{~kJ} \mathrm{~mol}^{-1}$ at $r \sim 2.8 \AA$. After the TOP site, in decreasing order of the adsorption strength, comes the $\mathrm{H} 1$ site, with a minimum binding energy of $\sim 17 \mathrm{~kJ} \mathrm{~mol}^{-1}$, at $r \sim 3 \AA$, for the $45 / 180$ orientation, and then the $\mathrm{H} 2$ site, with a minimum binding energy of $\sim 15 \mathrm{~kJ} \mathrm{~mol}^{-1}$, at $r \sim 2.7 \AA$, for the 90/180 orientation.

\section{Fitting the potential energy surface}

The molecular orientations and energies, obtained from the quantum calculations, only indicate the preferential behaviour for the adsorption of one ethanol molecule onto some specific sites of the gold cluster. Our aim, however, is to study the adsorption behaviour of an ensemble of ethanol molecules on a macroscopic surface, which will certainly depend on the thermodynamic conditions imposed upon the system and the multiple ethanol-ethanol and ethanol-electrode interactions. Therefore, it is necessary to perform simulations using a force field describing all interactions, including the ones for ethanol-gold at sites other than the specific ones chosen for the DFT calculations. 


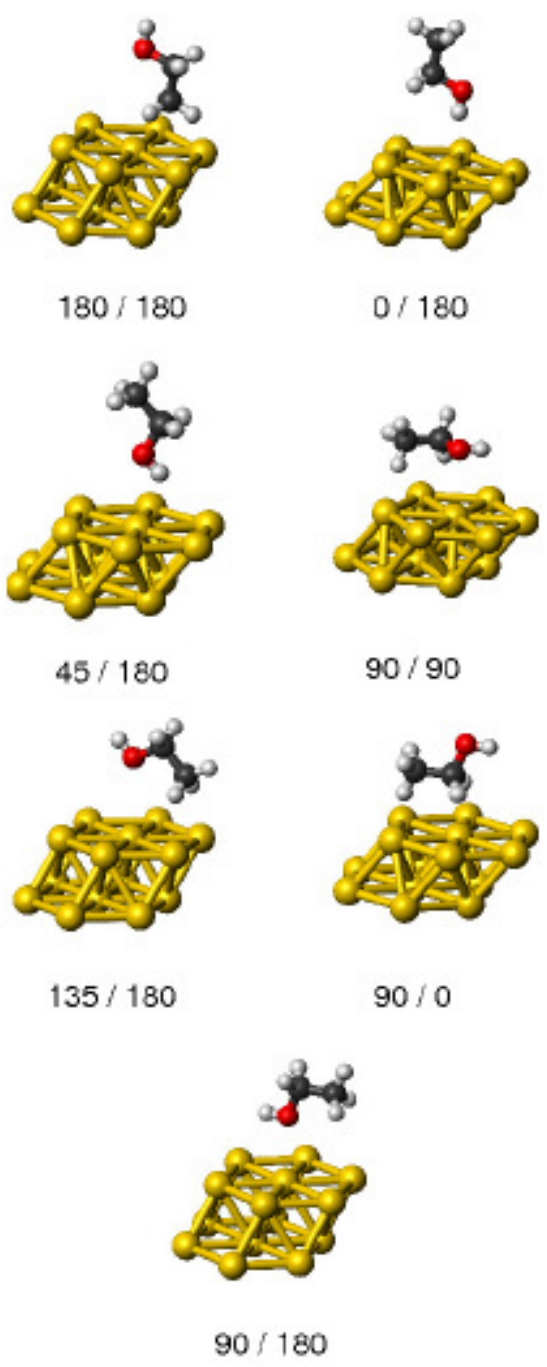

Figure 2. Selected orientations of the ethanol molecule relative to the Au(111) surface (notation $\alpha / \beta$, see text).

To this end, we developed an analytical force field to fit the quantum results, with the assumption that it can interpolate the situations not explicitly taken into account. The basis for the construction of the ethanol-Au(111) analytical PES was to take it as the sum of the interactions between each gold atom and the sites of the ethanol molecule further modulated by two angular contributions, one related to the TOP site surface symmetry and the other to the $\mathrm{O}-\mathrm{Au}$ relative direction. The ethanol molecule was described by a united atom model with the $\mathrm{H}, \mathrm{O}, \mathrm{CH}_{2}$ and $\mathrm{CH}_{3}$ as the interaction sites. The variables used are: the distance, $r$, from each $\mathrm{Au}$ atom to each of the ethanol sites; the angle, $\theta$, between the $\boldsymbol{r}_{\mathrm{O}-\mathrm{Au}}$ vector and the normal to the surface; and the angle, $\phi$, between the projection of the $\boldsymbol{r}_{\mathrm{O}-\mathrm{Au}}$ vector on the surface plane and a reference surface vector beginning in a TOP site and directed to a H1 site (see Fig. 4). 


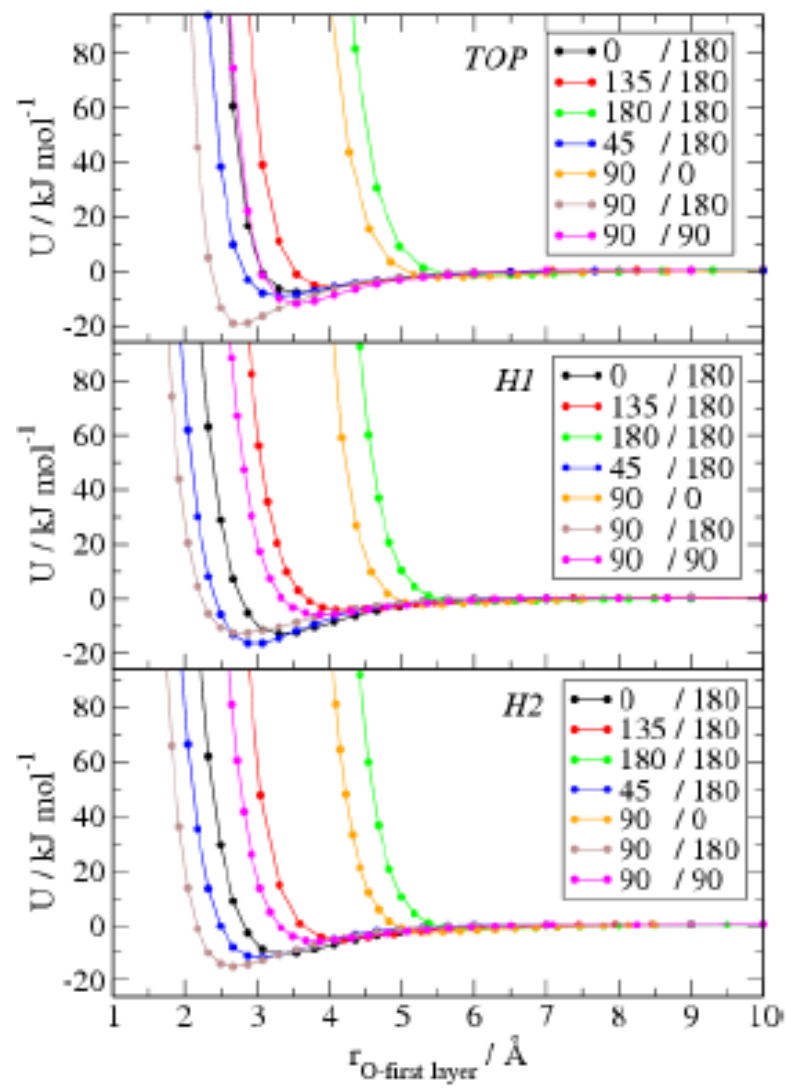

Figure 3. Potential energy values obtained by DFT. The lines are guides to the eye.

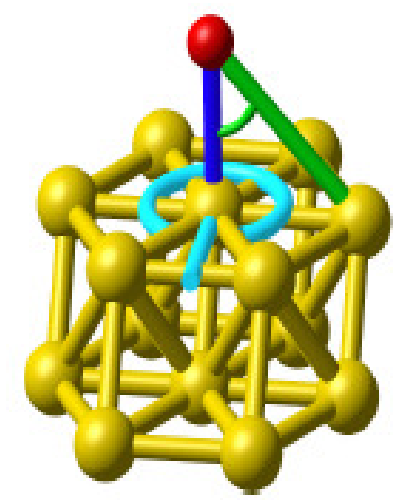

Figure 4. Angular degrees of freedom for the ethanol-Au(111) interaction. The angular dependence $\theta$ is represented by the angle in green (the oxygen atom is in red) and the angular dependence $\varphi$ is represented in light blue with the reference direction indicated by the cylinder of the same colour.

The selected function to represent the interaction between an ethanol molecule and a gold atom is:

$$
\begin{aligned}
\mathrm{U}_{\mathrm{EtOH}-\mathrm{Au}}= & \mathrm{U}_{\mathrm{H}}\left(\mathrm{r}_{\mathrm{H}-\mathrm{Au}}\right)+\left(1+\mathrm{B}_{0} \cos (\theta / \mathrm{rad})^{20} / \mathrm{r}_{\mathrm{O}-\mathrm{Au}}^{3}\right) \cdot \mathrm{U}_{\mathrm{O}}\left(\mathrm{r}_{\mathrm{O}-\mathrm{Au}}\right) \\
& +\mathrm{U}_{\mathrm{CH}_{2}}\left(\mathrm{r}_{\mathrm{CH}_{2}-\mathrm{Au}}\right)+\mathrm{U}_{\mathrm{CH}_{3}}\left(\mathrm{r}_{\mathrm{CH}_{3}-\mathrm{Au}}\right)+\mathrm{V}\left(\mathrm{r}_{\mathrm{O}-\mathrm{Au}}, \theta, \phi\right)
\end{aligned}
$$


where

$$
\mathrm{U}_{\mathrm{i}}\left(\mathrm{r}_{\mathrm{i}-\mathrm{Au}}\right)=\mathrm{A}_{0, \mathrm{i}} \exp \left[\mathrm{A}_{1, \mathrm{i}}\left(\mathrm{r}_{\mathrm{i}-\mathrm{Au}}+\mathrm{A}_{2, \mathrm{i}}\right)\right]-\mathrm{A}_{3, \mathrm{i}} \exp \left[\mathrm{A}_{4, \mathrm{i}}\left(\mathrm{r}_{\mathrm{i}-\mathrm{Au}}+\mathrm{A}_{5, \mathrm{i}}\right)\right]
$$

is the site-site interaction energy, and

$$
\begin{aligned}
\mathrm{V}\left(\mathrm{r}_{\mathrm{O}-\mathrm{Au}}, \theta, \phi\right)= & \mathrm{C}_{0} \sin (\theta / \mathrm{rad})^{6} \times \exp \left[\left(\mathrm{r} \sin (\theta / \mathrm{rad})-\mathrm{C}_{1}\right)^{2} / \mathrm{C}_{2}\right] \\
& \left.\times\left(\mathrm{C}_{3}-\mathrm{C}_{4} \cos \left(3(\phi / \mathrm{rad})-\mathrm{C}_{5}\right)\right)+\mathrm{C}_{6} \cos \left(6\left(\phi / \mathrm{rad}-\mathrm{C}_{5}\right)\right)\right)
\end{aligned}
$$

is the referred to contribution due to the surface symmetry around a TOP site.
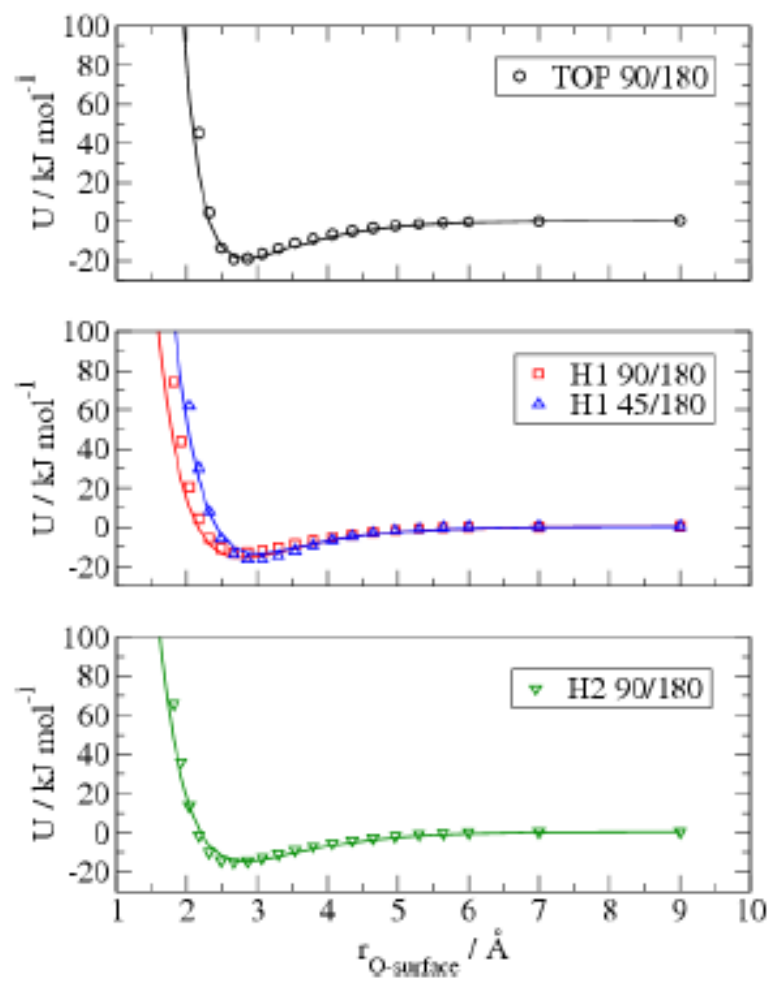

Figure 5. Fit of the DFT results for the most attractive orientations in each selected gold sites. The symbols represent the DFT values and the lines the fitted analytical force field.

The fit of the analytical PES to the DFT results was performed by means of genetic algorithms, using an $\mathrm{Au}(111)$ double layered electrode with $74 \mathrm{Au}$ atoms in order to minimize border effects from the surface. The details and the fitting parameters can be seen elsewhere [8]. The interaction energy between an ethanol molecule and the surface is calculated by the sum of $\mathrm{U}_{\mathrm{EtOH}-\mathrm{Au}}$ over all the $\mathrm{Au}$ atoms in the surface.

Fig. 5 presents the results of the fitting for the main orientations at each gold site. The fit for the TOP 90/180 and H2 90/180 curves is very good with less than $1 \mathrm{~kJ}$ $\mathrm{mol}^{-1}$ deviation from the DFT data at the minimum region. In the $\mathrm{H} 1$ case the 
most favourable orientation is the $45 / 180$ one, accordingly to DFT. However, the analytical function is not able to fully reproduce this situation since it gives the $90 / 180$ configuration as the most favourable. In the fit, the $45 / 180$ minimum is $13 \mathrm{~kJ} \mathrm{~mol}^{-1}\left(-17 \mathrm{~kJ} \mathrm{~mol}^{-1}\right.$ in DFT) and the $90 / 180$ one is $-15 \mathrm{~kJ} \mathrm{~mol}^{-1}\left(-13 \mathrm{~kJ} \mathrm{~mol}^{-1}\right.$ in DFT). As this is not the most important site for adsorption and the role of these two orientations does not change in a great extent, this aspect should have a minor influence in the molecular simulation results.

It is also important to analyse how the analytical function describes the interactions of each site of the ethanol molecule with gold, which only depend on the distances between the sites and the gold atoms. It will give an idea of the contributions of those single interactions to the whole ethanol-Au(111) PES and of the relative importance of each ethanol site in the adsorption process. The plots of $\mathrm{U}_{\mathrm{i}}\left(\mathrm{r}_{\mathrm{i}-\mathrm{Au}}\right)$, in equation 3 , are presented in Fig. 6. They clearly show that, in the present force field, the molecule should adsorb on the electrode from the $\mathrm{O}$ site and the other sites have repulsive contributions in order to control the allowed molecule orientations. Yet, the repulsive contributions of the $\mathrm{CH}_{2}$ and $\mathrm{CH}_{3}$ sites are felt at greater distances from the $\mathrm{Au}$ atoms than the one of the $\mathrm{H}$ site, due to their bigger size. These behaviours are in accordance with the insights provided by ab initio, DFT and experimental studies [9-12].

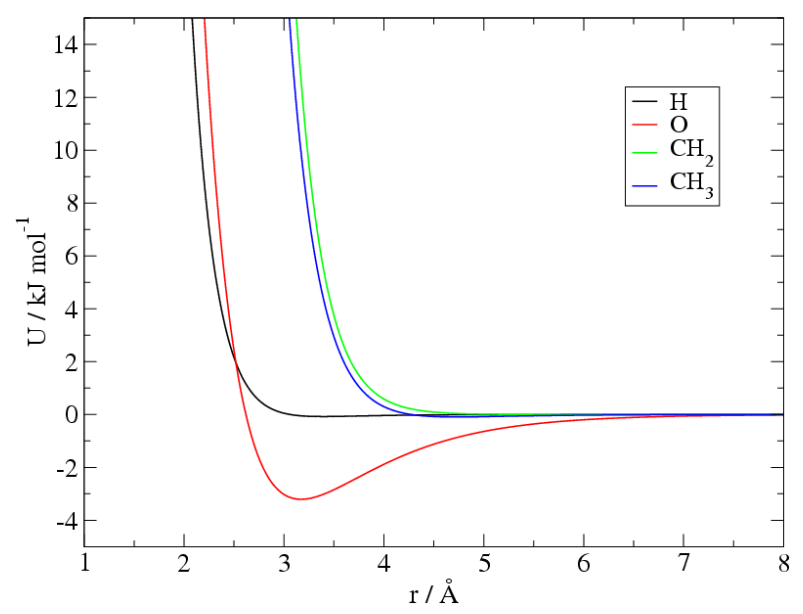

Figure 6. Individual ethanol site-Au atom interactions (Eq. 3).

\section{Monte Carlo simulations}

To test the proposed force field preliminary Monte Carlo (MC) simulations were performed in the canonical ensemble (NVT) at $298 \mathrm{~K}$. The computational details are presented elsewhere [8]. However, it is worth mentioning that the ethanolethanol inter and intra molecular interactions were modelled by the OPLS potentials of Jorgensen et al. [13].

The interfacial structure of the ethanol adsorption was analysed by calculating the normalised ethanol density profiles, presented in Fig. 7, along the normal to the electrode surface. 


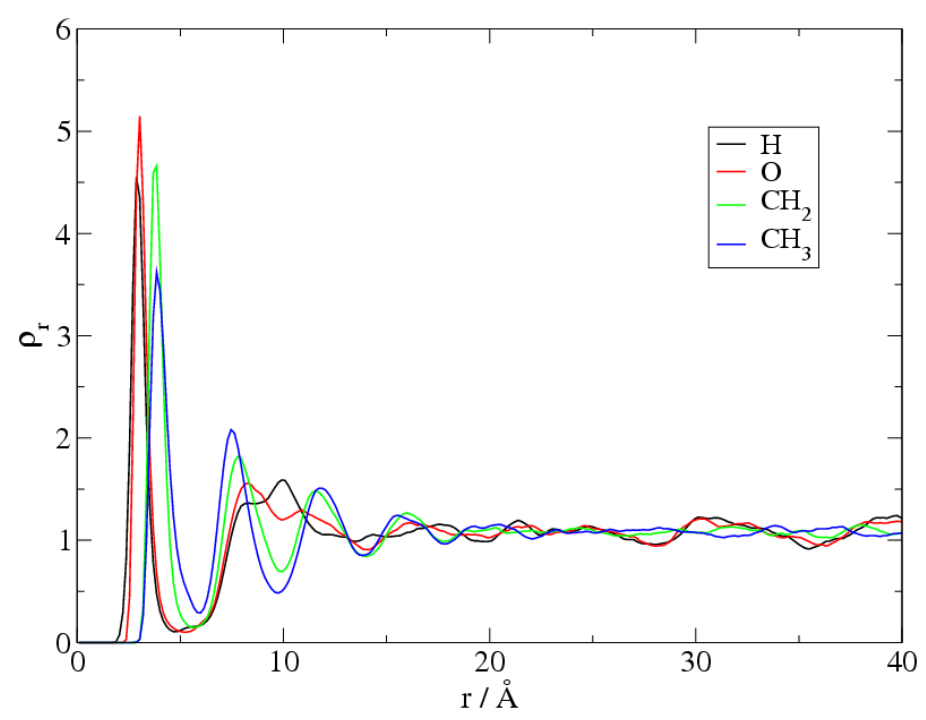

Figure 7. Ethanol density profiles along the normal to the electrode surface.

These give the relative density of each ethanol site as a function of the distance to the electrode. The profiles clearly show a well defined first adsorption layer, from $\sim 2$ to $6 \AA$ and two more diffuse layers, from $\sim 6$ to $9 \AA$ and $\sim 9$ to $13 \AA$. Also, apart from minor fluctuations, for distances beyond $\sim 15 \AA$ the relative density approaches unity as it would be expected in a bulk environment with no electrode influence. The first ethanol adsorption layer can also be observed in the snapshot of Fig. 8. In this layer the intense and narrow peaks (see Fig. 7) indicate that it is well organised, with the hydroxyl group attached to the electrode and the $\mathrm{CH}_{2}$ and $\mathrm{CH}_{3}$ sites turned to the bulk liquid. The position and the relative heights of the peaks for the $\mathrm{H}$ and $\mathrm{O}$ sites also show that ethanol adsorbs with the $\mathrm{OH}$ bond parallel to the electrode, in accordance to the most favourable orientation suggested by the DFT calculations for the TOP site. In the second adsorption layer the $\mathrm{CH}_{2}$ and $\mathrm{CH}_{3}$ sites are turned to the $\mathrm{CH}_{2}$ and $\mathrm{CH}_{3}$ sites of the first layer reflecting the interplay between the polar and non-polar molecular interactions. The third and most diffuse layer has a structure correlated with the second layer though in a minor degree. Therefore, according to the present results, the interfacial region for the ethanol adsorption on $\mathrm{Au}(111)$ surfaces covers the range of 2-15 $\AA$ with increasingly disorganization towards the bulk liquid.

Finally, although the DFT calculations were carried out up to a distance of $10 \AA$, where the ethanol-Au potential asymptotically approaches zero, the density profiles displayed in Fig. 7 show up correlations beyond that distance. They reflect the ethanol-ethanol interactions modelled by OPLS. Nonetheless, it is clear that up to $\sim 6 \AA$ a major contribution is from the ethanol-Au potential. 


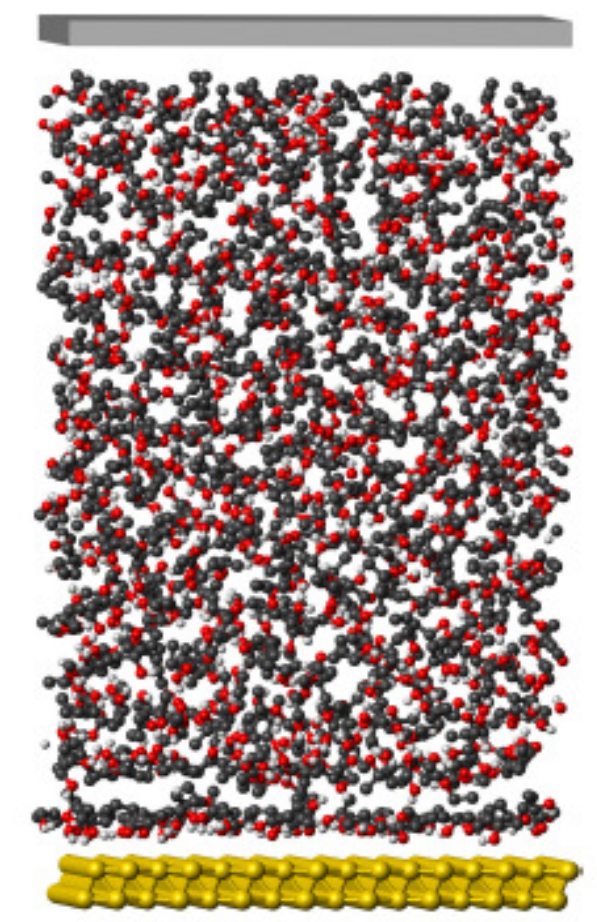

Figure 8. Last configuration of the production run for the ethanol + gold electrode + soft-wall system [8].

\section{Neural networks}

The strategy described in previous sections was to map the potential energy surface of ethanol-Au(111) through a set of DFT energies and to develop an analytical representation of such potential. A function that accurately matches the DFT data provides a topographical visualization of the surface features, which may not be evident from a coarse-grained quantum mechanical study. A good representation of the PES should smoothly connect the asymptotic as well as the most interactive regions of the configuration space. It should accurately represent the true potential energy in the regions for which experimental or theoretical results are available and predict the interaction energies for the regions where such data are not available.

In the study reported here the PES has six degrees of freedom and the development of the proposed fitting function was hard and slow. Therefore, it is foreseen that as the complexity of the systems increases the development of accurate analytical functions will turn out a non-trivial or even impossible task.

Recently, neural networks turned out as a suitable approach for estimating PES from $a b$ initio/DFT energy data sets. In such approximation there are no a priori guesses of analytical functions and the results come out in a tabular form. However, once the networks are well trained they are able to produce, as output, any required number of energy points for accurate numerical interpolations and extrapolations in simulation work. 


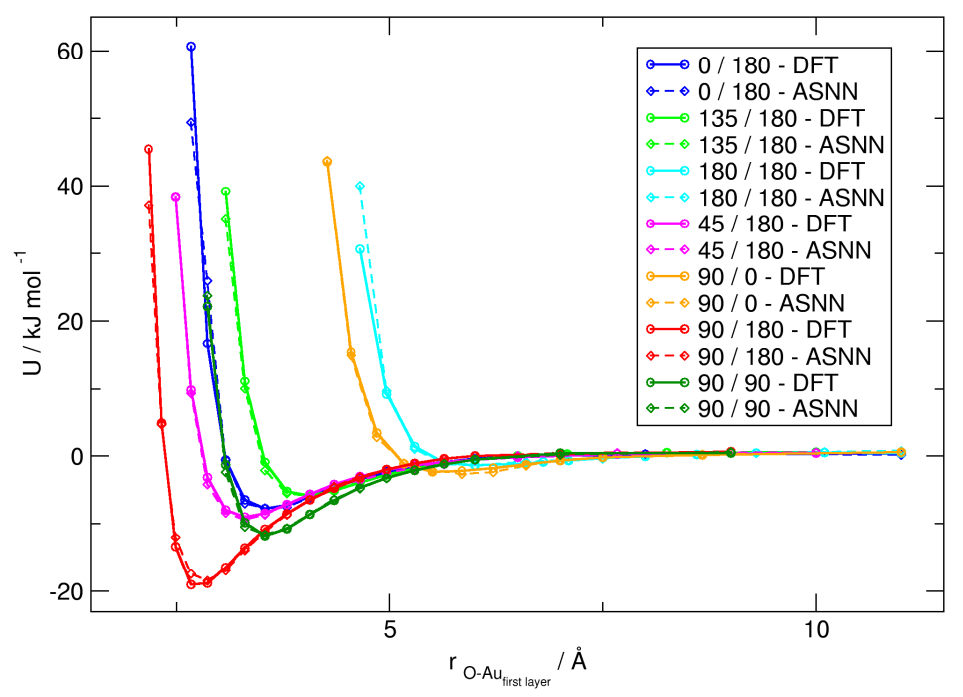

Figure 9. Potential energy values for the ethanol-Au(111) 14 in the top site by DFT and ASNN's trained with a data set of 366 energy points.

Fig. 9 displays some of our results for the ethanol-Au interaction energies obtained by associative neural networks (ASNN's) compared with the DFT results for the gold top site. It shows an excellent accordance. Fig. 10 represents one section of the PES obtained by the same method. General details of the methodology and tests of accuracy can be seen in a recent paper from our group, by Latino et al. [14].

$$
\text { Bele }
$$

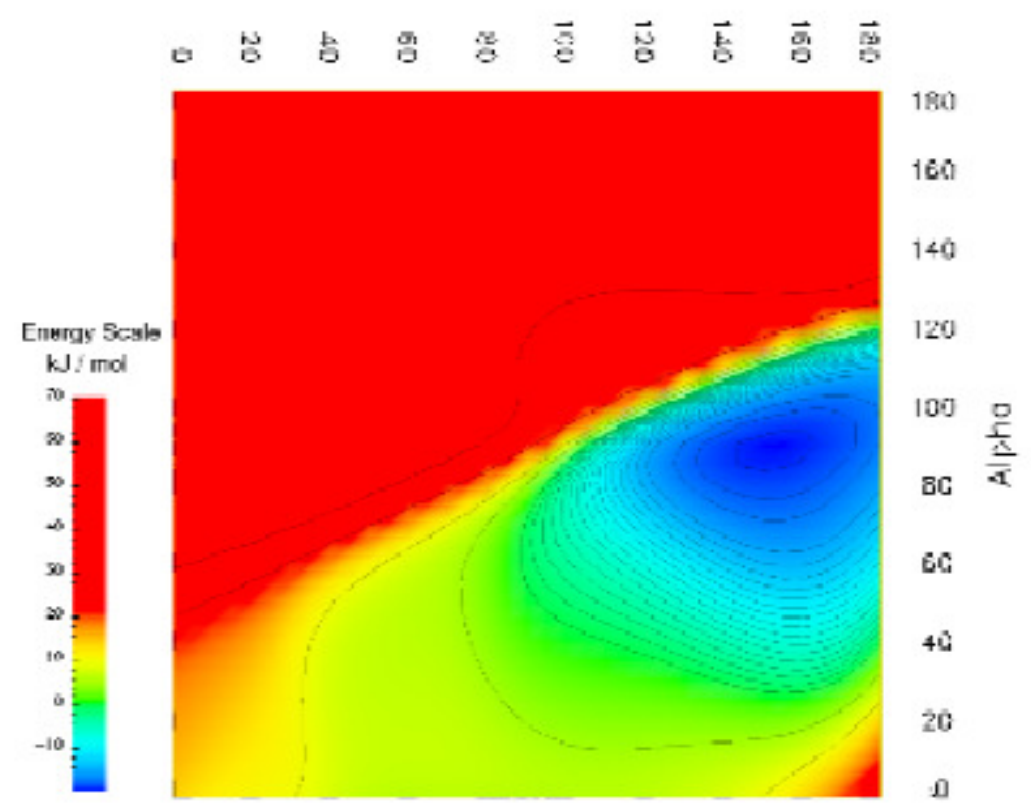

Figure 10. ASNN generated PES for the ethanol-Au(111) 14 in the top site with the ethanol molecule at a distance of $\sim 2.8 \AA$ from the surface. The alpha and beta angles are explained in the text. The potential energy scale is represented by the colour gradient from red (most repulsive part) to blue (most attractive part). 


\section{Final remarks}

This paper has reviewed one part of the research work in progress at our molecular simulation group. Further results on the adsorption and self-assembly of alkylthiols, from ethanol solutions, on gold electrodes, to be published soon, are already available in the recent Ph.D. thesis of Rui Fartaria [15]. Additionally, Diogo Latino is in the last year of his Ph.D. project, working enthusiastically on the approach of PES by neural networks.

I finish as I started, dedicating this article to Professor César Viana, who introduced me to the scientific research and guided me in many other ways. He was much more than a teacher and researcher. He was an upright man and, above all, a very, very good friend, whose memory will survive for ever.

\section{References}

1. M.H. Florêncio, J.C.R. Reis, Port. Electrochim. Acta 22 (2004) 177.

2. The Solid-Liquid Interface: a Challenge for Theoreticians, Symposium at the Spring Meeting of the Condensed Matter Division, German Physical Society, March 2007, Regensburg, Germany.

3. L.M. Abrantes, M. Kalaji, A.S. Viana, Química 74 (1999) 16.

4. R.G. Nuzo, F.A. Fusco, D.L. Allara, J. Am. Chem. Soc. 109 (1987) 2358.

5. J.D. Swalen, D.L. Allara, J.D. Andrade, E.A. Chandross, S. Garoff, J. Israelachvili, T.J. Mccarthy, Langmuir 3 (1987) 932.

6. A.S. Viana, A.H. Jones, L.M. Abrantes, M. Kalaji, J. Electroanal. Chem. 500 (2001) 290.

7. R.P.S. Fartaria, F.F.M. Freitas, F.M.S.S. Fernandes, J. Electroanal. Chem. 574 (2005) 321.

8. R.P.S. Fartaria, F.F.M. Freitas, F.M.S.S. Fernandes, Int. J. Quant. Chem. 107 (2007) 2169.

9. $\quad$ M.B. Knickelbein, G.M. Koretsky, J. Phys. Chem. A 102 (1998) 580.

10. R. Rosseau, G. Dietrich, S. Kruckerberg, K. Lutzenkirchen, D. Marx, L. Schweikhard, C. Walther, Chem. Phys. Lett. 295 (1998) 41.

11. R. Rosseau, D. Marx, J. Chem. Phys. 112 (2000) 761.

12. D.A. Outka, R.J. Madix, J. Vac. Sci. Technol. A 3 (1985) 1680.

13. W.L. Jorgensen, J. Phys. Chem. 90 (1986) 1276.

14. D.A.R.S. Latino, F.F.M. Freitas, J. Aires-de-Sousa, F.M.S.S. Fernandes, Int. J. Quant. Chem. 107 (2007) 2120.

15. R.P.S. Fartaria, Ph.D. Thesis, University of Lisboa, 2007. 